\title{
Inhibition of Human and Rat Sucrase and Maltase Activities To Assess Antiglycemic Potential: Optimization of the Assay Using Acarbose and Polyphenols
}

\author{
Alison Pyner, Hilda Nyambe-Silavwe, and Gary Williamson**i) \\ School of Food Science and Nutrition, University of Leeds, Woodhouse Lane, Leeds, Yorkshire LS2 9JT, U.K.
}

Supporting Information

ABSTRACT: We optimized the assays used to measure inhibition of rat and human $\alpha$-glucosidases (sucrase and maltase activities), intestinal enzymes which catalyze the final steps of carbohydrate digestion. Cell-free extracts from fully differentiated intestinal Caco-2/TC7 monolayers were shown to be a suitable source of sucrase-isomaltase, with the same sequence as human small intestine, and were compared to a rat intestinal extract. The kinetic conditions of the assay were optimized, including comparison of enzymatic and chromatographic methods to detect the monosaccharide products. Human sucrase activity was more susceptible than the rat enzyme to inhibition by acarbose $\left(\mathrm{IC}_{50}\right.$ (concentration required for $50 \%$ inhibition) $=2.5 \pm 0.5$ and $12.3 \pm 0.6 \mu \mathrm{M}$, respectively), by a polyphenol-rich green tea extract, and by pure $(-)$-epigallocatechin gallate $(\mathrm{EGCG})\left(\mathrm{IC}_{50}=\right.$ $657 \pm 150$ and $950 \pm 86 \mu \mathrm{M}$ respectively). In contrast, the reverse was observed when assessing maltase activity (e.g., EGCG: $\mathrm{IC}_{50}=677 \pm 241$ and $14.0 \pm 2.0 \mu \mathrm{M}$ for human and rat maltase, respectively). 5-Caffeoylquinic acid did not significantly inhibit maltase and was only a very weak inhibitor of sucrase. The data show that for sucrase and maltase activities, inhibition patterns of rat and human enzymes are generally qualitatively similar but can be quantitatively different.

KEYWORDS: $\alpha$-glucosidase, sucrase, maltase, green tea, EGCG

\section{INTRODUCTION}

The prevalence of type 2 diabetes has doubled over the last 30 years and affects an estimated 1 in 10 worldwide. ${ }^{1}$ A metaanalysis of intervention studies suggests that reducing the glycaemic impact of the diet can reduce the risk of developing type 2 diabetes. ${ }^{2}$ One current management strategy for diabetes is based on reducing the glycemic impact though inhibition of $\alpha$-glucosidase enzymes in the gut, and this can be achieved by regular consumption of the antihyperglycemic drugs acarbose, voglibose, and miglitol. ${ }^{3}$ In an intervention study where acarbose was taken daily for $3 \mathrm{yr}$, the risk for developing type 2 diabetes was reduced by $6 \%$ compared to the control. ${ }^{4}$ However, these drugs exhibit some gastrointestinal side effects, and so natural products are sought as possible alternatives or adjuncts.

Consumption of polyphenols has been associated with decreased incidence of type 2 diabetes and cardiovascular disease, ${ }^{5-7}$ in part owing to the potential for certain polyphenols to influence sugar digestion and absorption in the small intestine. ${ }^{8}$ Carbohydrate digestion can be attenuated by inhibition of $\alpha$-glucosidases such as sucrase and maltase and of monosaccharide transport across enterocytes. ${ }^{6}$ Because polyphenols have the potential to act in the same way as acarbose, this could also provide a mechanism for reduction in diabetes risk ascribed to polyphenol-rich diets. ${ }^{8}$ However, there are a number of limitations in the assays for assessing $\alpha$ glucosidase activities which could lead to misleading results and poor predictive capacity for subsequent in vivo testing in volunteers. Although human enzymes are always the intended target for therapeutic interventions, many studies have used the more readily available rat intestinal preparations in vitro. This is coupled with a variety of detection methods for the products, typically enzyme-linked spectrophotometric assays based on glucose oxidase or hexokinase, ${ }^{9-12}$ which are susceptible to inhibition themselves by the tested compounds, ${ }^{13}$ confounding estimation of inhibition of the target $\alpha$-glucosidase. Even though hexokinase was reported to be the method of choice, ${ }^{13}$ we report data here showing that polyphenols can substantially inhibit this enzyme.

The only intestinal enzyme able to hydrolyze sucrose is the enzyme sucrase. Sucrase isomaltase (SI) is a highly $\mathrm{N}$ - and $\mathrm{O}$ glycosylated brush border type-II membrane protein with various $\alpha$-glucosidase activities and is trafficked to the cell surface through association with lipid rafts. ${ }^{14}$ SI consists of two subunits, sucrase and isomaltase, which are cleaved by luminal proteases but remain associated through noncovalent interactions. ${ }^{15}$ The sucrase subunit has both maltase $(\alpha-1,4)$ and sucrase $(\alpha-1,2)$ activities, while the isomaltase subunit has maltase $(\alpha-1,4)$ and isomaltase $(\alpha-1,6)$ activities. $^{16}$ SI is therefore involved in the digestion of both sugars and starch. Type 2 diabetic patients have increased levels of SI, which potentially increases the rate of sugar digestion and uptake and exacerbates the problem, making it an interesting target for inhibition. ${ }^{17}$ Caco-2 cells express sucrase-isomaltose after differentiation and could be a suitable source of the enzyme for in vitro experiments. However, it is conceivable that the enzyme contains mutations in the cell line compared to human

Received: August 7, 2017

Revised: September 14, 2017

Accepted: September 15, 2017

Published: September 15, 2017 
tissue which, if present, could invalidate the use of the cell line as a source of genuine human enzyme.

Some studies have used Caco- 2 cells as a source of enzyme, where the inhibition of $\alpha$-glucosidases by mulberry leaves was tested, ${ }^{18}$ but the method did not take into account any subsequent transport and metabolism of the product. Other assays have been reported ${ }^{19,20}$ but not optimized. Given the potential importance of the assay in evaluating naturally occurring compounds for acarbose-like activity, the aim of this work was to optimize the assay for inhibition of human sucrase and maltase activities and evaluate differences in inhibition between the human and rat enzymes.

\section{MATERIALS AND METHODS}

2.1. Chemicals. Acarbose, 5-caffeoylquinic acid, sodium potassium monobasic, sodium potassium dibasic, glucose, sucrose, maltose, hexokinase glucose assay reagent, Bradford reagent, intestinal acetone powder extract from rat, protease inhibitors, epigallocatechin gallate, trypsin EDTA solution, L-cysteine, papain from papaya latex, Dulbeccos's modified Eagle's Medium, nonessential amino acids, penicillin-streptomycin solution, phosphate buffered saline (PBS), and fetal bovine serum were purchased from Sigma-Aldrich, Dorset, UK. Glutamax was from Thermo Fisher Scientific, Waltham, MA, United States. Oasis MAX cartridges were purchased from Waters Corporation, Milford, MA, United States. Green tea water-soluble extract was from Nestlé, Choladi, India. The Caco2/TC7 cell line was a kind gift by Prof. Monique Rousset, Centre de Recherche des Cordeliers, Paris, France. The green tea extract was analyzed by $\mathrm{HPLC}^{21}$ and contained $199.8 \mathrm{mg} / \mathrm{g}(-)$-epigallocatechin gallate, 124.4 $\mathrm{mg} / \mathrm{g}(-)$-epigallocatechin, $34.4 \mathrm{mg} / \mathrm{g}(-)$-epicatechin gallate, and $23.3 \mathrm{mg} / \mathrm{g}(-)$-epicatechin $(\mathrm{w} / \mathrm{w})$.

2.2. Equipment Used for Measurement of Enzyme Activity. Absorbance measurements were performed on a Pherastar FS plate reader from BMG labtech, Ortenberg, Germany. High performance anion exchange chromatography with pulsed amperometric detection (HPAE-PAD) was performed on the ICS4000 system from Thermo Fisher Scientific.

2.3. Gene Sequencing. The sequencing of SI from Caco- $2 / \mathrm{TC} 7$ cells used the following materials: RNAqueous Total RNA Isolation kit from Thermo Fisher Scientific, GoScript Reverse Transcription System from Promega, Madison, WI, United States, Cloneamp HiFi PCR premix and In-fusion cloning kit from Takara Bio Europe, SaintGermain-en-Laye, France, primers from Sigma-Aldrich, Dorset, UK, and zymoclean gel extraction PCR recovery kit from Zymo Research, California, United States. Human RNA as a reference sample for sucrase sequencing was from DV Biologics, California, United States.

2.4. Growth Conditions for Caco-2 Cells as a Source of Human Enzyme for in Vitro Assays. Caco-2/TC7 cells were routinely cultured at a density of $1.2 \times 10^{6}$ cells per $75 \mathrm{~cm}^{2}$ culture flask in standard medium consisting of Dulbeccos's modified Eagle's Medium supplemented with $20 \%(\mathrm{v} / \mathrm{v})$ fetal bovine serum, $2 \%(\mathrm{v} / \mathrm{v})$ Glutamax, 2\% (v/v) nonessential amino acids, and $1 \%$ penicillinstreptomycin solution. Cells were maintained in an incubator at $37{ }^{\circ} \mathrm{C}$ with $10 \% \mathrm{CO}_{2}$. Medium was replaced every $2 \mathrm{~d}$ and, at this seeding density, $80 \%$ confluence was reached in $3 \mathrm{~d}$, at which point the cells were subcultured by detaching with $0.25 \%$ trypsin. Cells were allowed to fully differentiate for $21 \mathrm{~d}$, and a crude lysate was prepared. The cells were washed 3 times with cold phosphate buffered saline and cells were scraped with $1 \mathrm{~mL}$ of assay buffer $(10 \mathrm{mM}$ phosphate buffer, $\mathrm{pH}$ $7.0)$ containing protease inhibitors. The cell lysates were snap frozen in a dry ice and ethanol bath and stored at $-80{ }^{\circ} \mathrm{C}$ until required. On the day of assay, cell lysates were thawed, vortexed, and then passed $10-15$ times though a $21 \mathrm{G}$ needle syringe, and this preparation is referred to as a cell-free extract because it contains no intact cells. Papain-digested lysates were also prepared to evaluate different lysate preparation methods. Fully differentiated cells were washed with warm PBS and then incubated at $37{ }^{\circ} \mathrm{C}$ for 15 min with $2 \mathrm{~mL}$ papain solution containing $1 \mathrm{mg} / \mathrm{mL}$ papain and $0.5 \mathrm{mg} / \mathrm{mL}$ L-cysteine. ${ }^{22}$
After the incubation, cells were scraped and transferred into Eppendorf tubes and centrifuged at $210 \mathrm{~g}$ for $10 \mathrm{~min}$ at $4{ }^{\circ} \mathrm{C}$. The supernatant was used for the assay. The protein content of the lysate, either crude or papain-digested, was determined by Bradford assay, ${ }^{23}$ and the lysate was diluted in assay buffer as required.

2.5. Extraction of mRNA from Caco-2/TC7 Cells, Conversion to CDNA, and Sequencing of CDNA for Sucrase Isomaltase. Total RNA was extracted using the RNAqueous Total RNA Isolation kit according to the manufacturer's protocol, and then $250 \mathrm{ng}$ of total RNA was converted into cDNA by reverse transcription using the reverse transcription kit according the manufacturer's protocol. The gene was reverse transcribed in two parts with two sucrase-isomaltase specific reverse primers $\mathrm{A}$ and $\mathrm{B}$ and amplified using primer pairs specific to each segment (see Table S1) using Cloneamp HiFi PCR premix. Primers contained overlapping ends for future cloning into a vector (underlined and in italics). The PCR products from segment A (bases 1-1811) and segment B (1174-5784) were separated on an agarose gel extracted using Zymoclean gel extraction PCR recovery kit and then cloned together using the In-fusion cloning kit. This kit uses a recombinase enzyme which fuses the overlapping homologous sequences together and resulted in the full SI coding region, which was sent for DNA Sanger sequencing by Beckman Coulter Genetics using the primers as found in Table S2. The RNA from a human intestinal biopsy from DV Biologics was sequenced as a reference using the same procedure.

2.6. Sucrase and Maltase Assays Using a Caco-2 TC7 CellFree Extract. Assay samples of $250 \mu \mathrm{L}$ contained sucrose or maltose, with Caco-2/TC7 cell lysate preparation as the enzyme source in 0.1 $\mathrm{M}$ phosphate buffer $\mathrm{pH}$ 7.0. A time course was evaluated from 0 to 30 $\mathrm{min}$, and assays to determine the specific activity in the lysate were performed with a range of enzyme concentrations (total protein from 40 to $320 \mu \mathrm{g}$ ). The specific activity was determined as the amount of substrate consumed per minute per $\mathrm{mg}$ of total protein in the assay. The kinetic parameters $K_{\mathrm{m}}$ and $V_{\max }$ were determined using initial rates derived from the selected enzyme concentration and incubation times with substrate concentrations ranging from 1 to $60 \mathrm{mM}$. One enzyme unit $(\mathrm{U})$ is equivalent to the amount of enzyme that catalyzes the hydrolysis of $1 \mu \mathrm{mol}$ of substrate per min. For inhibition assays, inhibitor was added to the reaction mixture at the indicated concentrations: acarbose from 1 to $50 \mu \mathrm{M}$, EGCG from 100 to $1500 \mu \mathrm{M}$, GT from 0.5 to $5 \mathrm{mg} / \mathrm{mL}$, and 5-caffeoylquinic acid from 100 to $500 \mu \mathrm{M}$. For inhibitors dissolved in DMSO to ensure solubility (EGCG and 5-caffeoylquinic acid), control samples were included to ensure no interference, and a maximum of $2 \%$ of the total reaction volume was DMSO. Assay samples were incubated in a water bath at $37^{\circ} \mathrm{C}$ for $10 \mathrm{~min}$, and the reaction was stopped by placing the samples in a boiling water bath for $10 \mathrm{~min}$. Samples were centrifuged at $17000 \mathrm{~g}$ for $10 \mathrm{~min}$.

2.7. Glucose Detection Methods: Hexokinase and HPAEPAD. The glucose produced in the enzyme reaction was quantified enzymatically using hexokinase according to the manufacturer's protocol or chromatographically with HPAE-PAD, which has been reported previously to measure glucose. ${ }^{24,25}$ Using HPAE-PAD, glucose was chromatographically separated from fructose and sucrose and could be quantified between 1 and $50 \mu \mathrm{M}$. Before HPAE-PAD analysis, protein in the samples was precipitated by the addition of acetonitrile $(1: 1 \mathrm{v} / \mathrm{v})$, and samples were vortexed and centrifuged at $17000 \mathrm{~g}$ for $10 \mathrm{~min}$. The resulting supernatant was diluted with deionized water to fall within the calibration range, filtered through a $0.2 \mu \mathrm{M}$ PTFE filter, and maintained at $4{ }^{\circ} \mathrm{C}$ in the autosampler. Capillary separation of carbohydrates was done using the capillary CarboPac PA20 column, $0.4 \times 150 \mathrm{~mm}$ with CarboPac PA20 Guard, $0.4 \times 35 \mathrm{~mm}$ with the column at $30^{\circ} \mathrm{C}$ and compartment at $15{ }^{\circ} \mathrm{C}$. The detection was performed using a gold working electrode and palladium reference electrode with a collection rate of $2.00 \mathrm{~Hz}$ using the waveform "Gold, Carbo, Quad" waveform. The analysis method starts at $25 \mathrm{mM} \mathrm{NaOH}$ eluent for $10 \mathrm{~min}$ followed by a wash at 100 $\mathrm{mM}$ for $15 \mathrm{~min}$ and then re-equilibration at $25 \mathrm{mM}$ from 25 to $38 \mathrm{~min}$. The flow rate was $0.008 \mathrm{~mL} / \mathrm{min}$ with $0.04 \mu \mathrm{L}$ injection volume and 20x capillary overfill. Inhibitors were evaluated for potential 
interference by preparing and analyzing assay samples without substrate containing inhibitor at the highest concentration used.

2.8. Effect of Polyphenols on Hexokinase-Linked Assay and Removal by SPE. To evaluate which polyphenols or polyphenol-rich extracts interfere with the hexokinase assay, samples $(250 \mu \mathrm{L})$ containing $5 \mathrm{mM}$ glucose were prepared in assay buffer with and without polyphenols or extracts at their highest tested concentration (see Section 2.6 above). The assay was performed using hexokinase to measure the amount of glucose, and the samples were compared to the control. The independent sample $t$ test was performed to determine if the inhibitors had significant effect on the assay. Any inhibitors which interfered significantly were removed by SPE prior to analysis in all subsequent assays as follows: Oasis MAX $3 \mathrm{cc}$ cartridges were preconditioned with $1 \mathrm{~mL}$ of deionized water and $1 \mathrm{~mL}$ of methanol and then dried under vacuum for $5 \mathrm{~min}$. The sample collection tube was placed under the cartridge, and $200 \mu \mathrm{L}$ of test samples and controls were passed through and collected. A fixed volume was then used in the hexokinase assay as indicated above. Removal of any interference by SPE was confirmed by evaluating separate polyphenol samples spiked with glucose.

2.9. Sucrase and Maltase Assay Using a Rat Intestinal Acetone Protein Extract. The enzyme assay was also optimized for incubation time, substrate concentration, and linear range using an enzyme preparation from powdered acetone protein extract from rat intestine. ${ }^{21}$ For maltase, $4 \mathrm{mg}$ solid $/ \mathrm{mL}$ was used with $3 \mathrm{mM}$ maltose and $20 \mathrm{~min}$ incubation time. For sucrase, $20 \mathrm{mg}$ solid $/ \mathrm{mL}$ was used with $16 \mathrm{mM}$ sucrose and $20 \mathrm{~min}$ incubation time.

3.0. Data and Statistical Analysis. The percent inhibition was determined by the following formula where the control is without inhibitor:

$$
\%=\frac{\left([\text { glucose }]_{\text {control }}-[\text { glucose }]_{\text {inhibitor }}\right)}{[\text { glucose }]_{\text {control }}} \times 100
$$

Statistics were performed by one-way analysis of variance using SPSS Statistics version 24, and statistical significance was determined by Tukey-Kramer multiple comparison test $(p \leq 0.05)$. The data are presented as mean \pm SEM with minimum of $n=3$. Cell lysates were prepared from three biological passages of cells and used for $\mathrm{IC}_{50}$ determinations.

\section{RESULTS}

3.1. Sucrase Isomaltase from Caco-2/TC7 Cells and Human Small Intestine Has the Same Sequence, Showing That the Former Is a Suitable Source of Enzyme for in Vitro Assays. One of the goals was to optimize an assay for assessing inhibition using human differentiated Caco-2/TC7 cell extracts as a source of the sucrase-isomaltase. Only the sucrase sequence from Caco-2 cells, and not from Caco-2/TC7 cells, has been reported, ${ }^{26}$ and because even point mutations may under some circumstances lead to alteration of enzyme activity, ${ }^{14}$ it was important to establish that the sucrase sequence of the Caco-2/TC7 line was the same as the human small intestinal enzyme. Based on sequencing of sucrase from the Caco-2/TC7 clone, we confirm that it has a sequence identical to that of the human intestine (sequencing results from Caco-2/TC7 are shown in Supporting Information, Section S3). The reported Caco-2 cell sucrase sequence, ${ }^{26}$ the reference human biopsy control sample from DV Biologics, and the BC132860.1 sequence from the National Institutes of Health Mammalian Gene Collection (MGC) Program $^{27}$ all reported the same sequence as that in the Caco2/TC7 cells. However, it should be noted that there is one base different at position $4632(\mathrm{G} \rightarrow \mathrm{A})$ compared to one of the sequences in the NCBI database (NM 001041.3).

3.2. Optimization of Human Sucrase-Isomaltase Assay: Determination of Kinetic Parameters, Substrate
Concentration Dependence, and Assay Time Course Linearity. A cell-free extract from Caco-2/TC7 cells was evaluated as a source of sucrase and maltase for use in assays. A time course was determined using $10 \mathrm{mM}$ sucrose and maltose, and maltase exhibited a linear production of glucose up to 15 min (Figure 1A) with sucrase linear up to $40 \mathrm{~min}$ (Figure 1B).

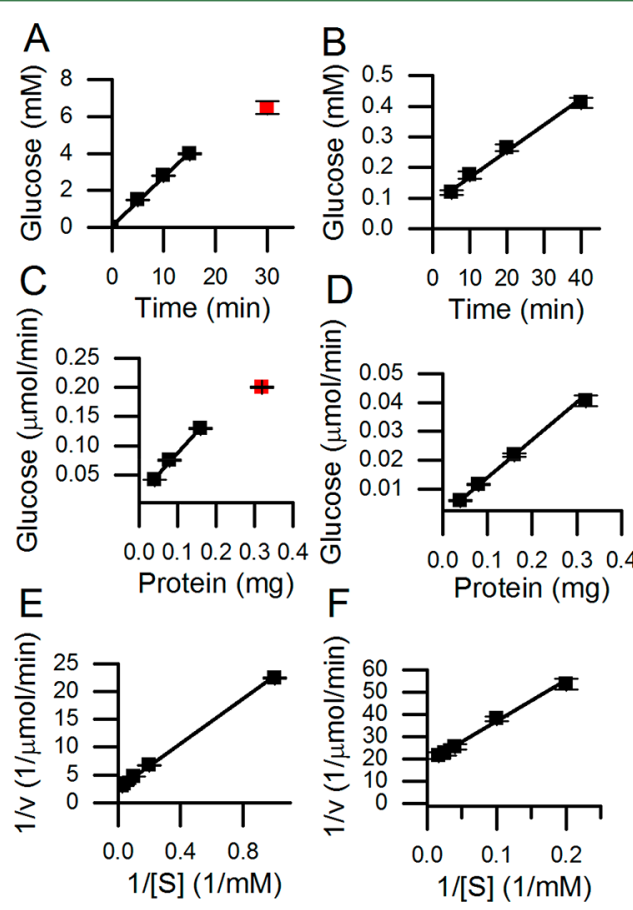

Figure 1. Optimization of assay parameters using cell-free extracts from human Caco2/TC7 cells. Human maltase activity time course (A), dependence on added protein (C), and Lineweaver-Burk plot for determination of $K_{\mathrm{m}}$ and $V_{\max }(\mathrm{E})$. Human sucrase activity time course (B), dependence on added protein (D) and Lineweaver-Burk plot for determination of $K_{\mathrm{m}}$ and $V_{\max }(\mathrm{F})$. Solid lines indicate the linear part of the curve. Error bars where not visible are smaller than the data point. Results are presented as mean $\pm \operatorname{SEM}(n=3)$.

On the basis of this, an assay time of 10 min was selected for both activities. The specific activity of maltase was $725 \pm 36$ $\mathrm{mU} / \mathrm{mg}$ (Figure 1C) and for sucrase was $130 \pm 4 \mathrm{mU} / \mathrm{mg}$ (Figure 1D) and was proportional to total protein up to 1.28 and $0.64 \mathrm{mg} / \mathrm{mL}$, respectively. The amount of protein chosen for future assays was selected to ensure a linear initial rate: 0.05 and $0.02 \mathrm{U}$ per assay for maltase and sucrase, respectively. Using the conditions established, the apparent $K_{\mathrm{m}}$ was $9.5 \mathrm{mM}$ and $V_{\max }=0.053 \mu \mathrm{mol} / \mathrm{min}$ for sucrose, and apparent $K_{\mathrm{m}}$ was $7.5 \mathrm{mM}$ and $V_{\max }=0.379 \mu \mathrm{mol} / \mathrm{min}$ for maltose (Figures $1 \mathrm{E}$ and $\mathrm{F}$, respectively). The sucrase and maltase apparent $K_{\mathrm{m}}$ values measured here were within the reported range for human sucrase ${ }^{19,20,28}$ and for human maltase. ${ }^{20}$ Optimizing the assay is extremely important to correctly evaluate and identify inhibitors. Using the optimized assay conditions, acarbose inhibited maltase activity (Figure 2 ) with an $\mathrm{IC}_{50}$ value of $5.7 \pm$ $1.4 \mu \mathrm{M}$. When more enzyme was used ( $0.2 \mathrm{U} /$ assay), the reaction rate became nonlinear, and the $\mathrm{IC}_{50}$ value for acarbose was estimated at $22.1 \pm 2.9 \mu \mathrm{M}$ (Figure 2), which was 4-fold higher. Varying the substrate concentration had a less dramatic effect on the measured $\mathrm{IC}_{50}$ value. For sucrase, the measured $\mathrm{IC}_{50}$ value for acarbose was unchanged over a 100 -fold variation in substrate concentration (Figure 3A). For maltose, there was 


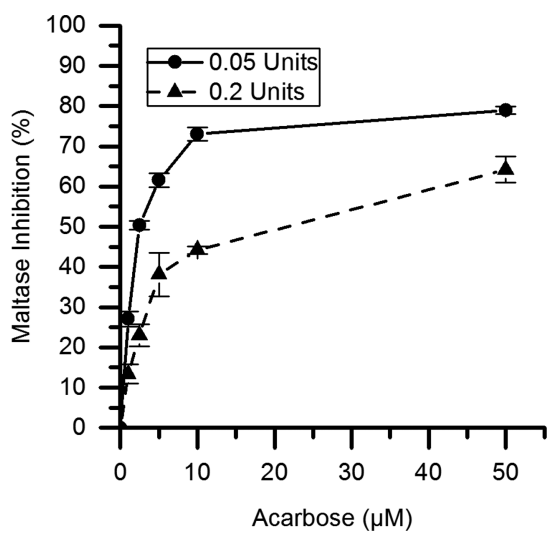

Figure 2. The effect of amount of enzyme in the assay for the inhibition of maltase by acarbose. Results are presented as mean \pm $\operatorname{SEM}(n=3)$.

a small effect on the measured $\mathrm{IC}_{50}$ value when the substrate concentration was greater than $10 \times$ the $K_{\mathrm{m}}$ (Figure 3B).

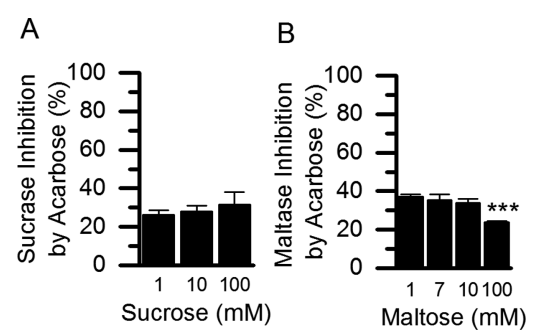

Figure 3. Effect of substrate concentration on apparent inhibition. Substrate concentrations of $1,10\left(\sim K_{\mathrm{m}}\right)$, and $100 \mathrm{mM}$ were evaluated for sucrose (A) and 1, $7\left(\sim K_{\mathrm{m}}\right), 10$, and $100 \mathrm{mM}$ for maltose (B) were used in the assay for inhibition by acarbose at $2.5 \mu \mathrm{M}$. Results are presented as mean $\pm \operatorname{SEM}(n=3)$.

3.4. Effect of Papain Treatment on Enzyme Activities. Sucrase-isomaltase is attached via a protein tail to the small intestine brush border membrane. To determine if there could be an advantage in removing it from the cellular membrane, we used papain to release the enzyme from the brush border. Although papain treatment gave an increase the specific activity of both sucrase and maltase (Figures $4 \mathrm{~A}$ and $\mathrm{B}$ ), the inhibition observed was unchanged (Figures $4 \mathrm{C}$ and $\mathrm{D}$ ). It was therefore concluded that the papain step did not offer a significant advantage to the overall method for determining inhibition.

3.5. Determination of Possible Interference in the Hexokinase-Linked Estimation of Glucose. Hexokinase and glucose oxidase are commonly used enzymes for assessing glucose concentration and both are commercially available in the form of kits. Glucose oxidase is highly susceptible to inhibition by polyphenols and other compounds, ${ }^{13,29}$ and although hexokinase is less susceptible, it is still reported to be inhibited. ${ }^{13}$ All compounds tested here were evaluated here for direct inhibition of hexokinase. Glucose standards at $1 \mathrm{mM}$ were prepared in presence and absence of each inhibitor, and the concentration of glucose was determined using the hexokinase assay. EGCG at $1000 \mu \mathrm{M}$ led to an apparent $23 \%$ increase in glucose concentration $(p<0.001, n=3)$; green tea at $2.5 \mathrm{mg} / \mathrm{mL}$ caused an apparent $13 \%$ decrease in glucose concentration ( $p=0.002, n=3)$, and 5-caffeoylquinic acid at $500 \mu \mathrm{M}$ caused an apparent decrease of $10 \%(p<0.001, n=3)$. Acarbose at $100 \mu \mathrm{M}$ had no significant effect on the assay

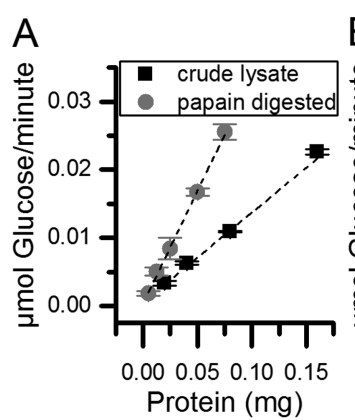

B
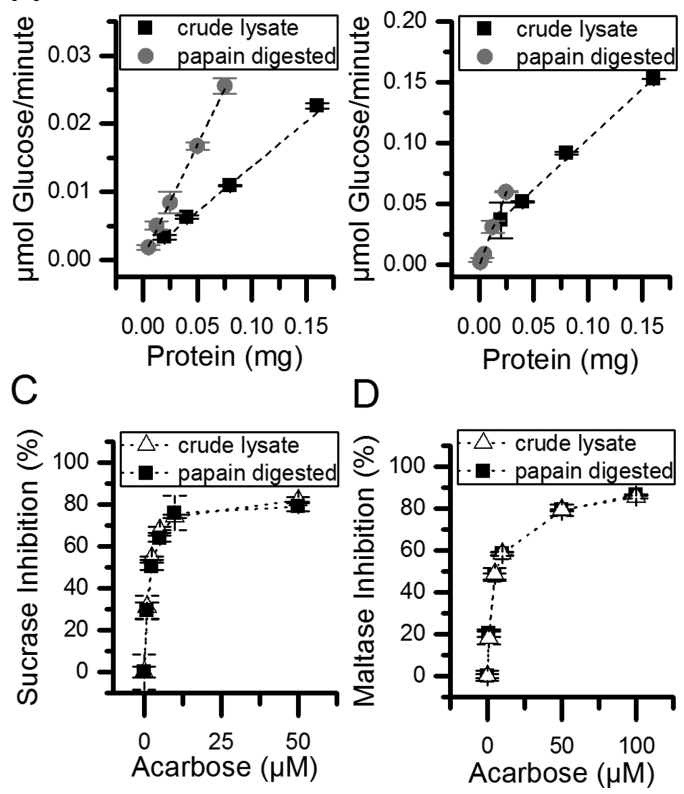

D

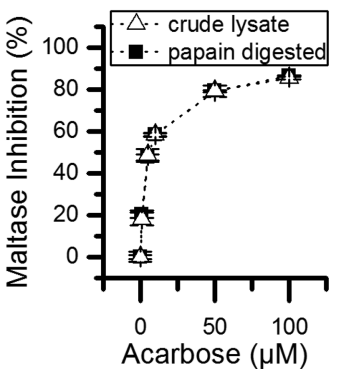

Figure 4. Effect of papain treatment on enzyme activity and inhibition. Caco-2/TC7 crude lysate or the supernatant from papain-digested was used as the enzyme source for sucrase (A) or maltase (B) assay with $10 \mathrm{mM}$ substrate, $10 \mathrm{~min}$ incubation time, and increasing amounts of total protein. Acarbose inhibition of sucrase (C) and maltase (D) determined using both preparations with $10 \mathrm{mM}$ substrate, $10 \mathrm{~min}$ incubation time, and increasing concentrations of acarbose. Results are presented as mean $\pm \mathrm{SD}(n=3)$.

compared to the control $(p=1.0, n=3)$. These results indicate that EGCG, green tea, and 5-caffeoylquinic acid all inhibited hexokinase activity, whereas acarbose did not. On the basis of these results, EGCG, green tea, and 5-caffeoylquinic acid must be removed before assessing glucose production by sucrase or maltase activities. SPE removal was tested and proved to successfully remove all of the polyphenols before analysis using hexokinase and so was incorporated into the protocol.

3.6. Comparison of Methods for Detection of Sugars. Because several of the test compounds were shown to interfere with the hexokinase assay, chromatographic quantitation of sugars using HPAE-PAD was evaluated as a potential alternative for estimation of product compared to the enzymatic detection. Glucose is readily quantified using this method. $^{24,25}$ Good separation was achieved between glucose, fructose, and sucrose, and a standard curve for glucose was linear between 1 and $50 \mu \mathrm{M}$ (Figures 5A and B) with limit of detection $=0.5 \mu \mathrm{M}$ and of quantitation $=1.0 \mu \mathrm{M}$. Sucrose hydrolysis led to formation of glucose and fructose (Figure 5C); inhibition by EGCG was readily observed as a reduction in glucose and fructose peaks (Figure 5C), but when used as a substrate, sucrose was not normally measured as the peak for this sugar was saturated. For maltose as substrate, inhibition was apparent as a reduction in the glucose peak (Figure 5D). The inhibitors tested here were also run to determine if they contained any sugars or generated any interfering peaks. Of the tested samples, only green tea contained glucose (Figure 6); at $5 \mathrm{mg} / \mathrm{mL}$, it contained $0.36 \mathrm{mM}$ glucose, reduced after SPE to $0.14 \mathrm{mM}$ owing to dilution. The amount of glucose quantified in enzyme assays after hydrolysis typically ranged from 0.4 to 2 $\mathrm{mM}$, and so the glucose present in green tea $(\leq 0.14 \mathrm{mM})$ would significantly interfere. Green tea standards were prepared 

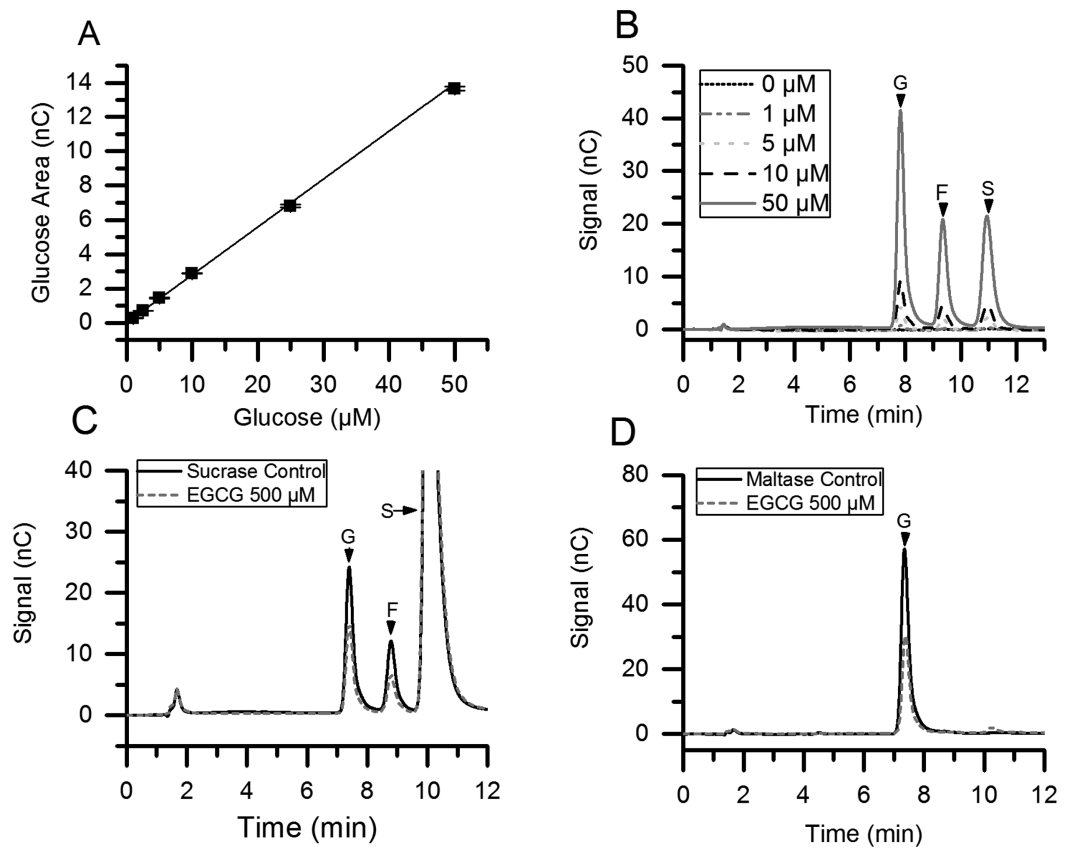

Figure 5. Chromatographic estimation of sugars. Calibration curve for the quantification of glucose standards by HPAE-PAD (A) as mean \pm SEM (linear fit $y=0.274 x ; r^{2}=0.99$; average relative standard deviation $3.4 \%, n=4$, injection volume $0.04 \mu \mathrm{L}$ ) and representative chromatograms for standards containing a mixture of glucose, fructose, and sucrose (B) where $\mathrm{G}=$ glucose, $\mathrm{F}=$ fructose and $\mathrm{S}=$ sucrose. Example chromatograms showing sugar analysis from sucrase (C) or maltase (D) assays with and without EGCG at $500 \mu \mathrm{M}$.

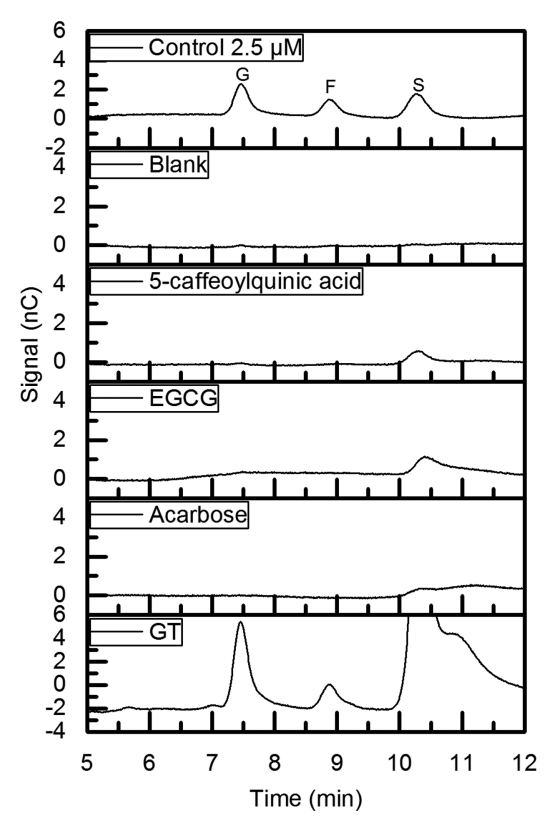

Figure 6. Evaluation of interference in chromatographic analysis of sugars. Inhibitors were directly added at their highest evaluated concentration to assays containing no substrate. The control was spiked with $2.5 \mu \mathrm{M}$ glucose $(\mathrm{G})$, fructose $(\mathrm{F})$, and sucrose $(\mathrm{S})$.

over a range of concentrations and used to correct for the sugar content.

To compare the chromatographic method with the hexokinase-linked assay, maltase assays with and without EGCG were analyzed by both methods (Table1). Before glucose analysis by hexokinase but not HPAE-PAD, EGCG was removed by SPE. The hexokinase-linked method showed $\sim$ twofold greater variation than the chromatographic method based on glucose detection (Table 1). The absolute
Table 1. Comparison of Methods for Glucose Detection When Assessing the Inhibition of Human Maltase Activity by EGCG $^{a}$

\begin{tabular}{lccccc} 
& \multicolumn{2}{c}{ SPE/hexokinase } & & \multicolumn{2}{c}{ no SPE/HPAE-PAD } \\
\cline { 2 - 3 } \cline { 5 - 6 } $\begin{array}{c}\text { EGCG } \\
(\mu \mathrm{M})\end{array}$ & $\begin{array}{c}\text { measured glucose } \\
(\mathrm{mM})\end{array}$ & $\begin{array}{c}\text { \% CV } \\
0\end{array}$ & & $\begin{array}{c}\text { measured glucose } \\
(\mathrm{mM})\end{array}$ & \% CV \\
0 & $1.7 \pm 0.2$ & 8.6 & & $2.7 \pm 0.1$ & 2.6 \\
100 & $1.1 \pm 0.0$ & 2.4 & & $2.1 \pm 0.1$ & 3.6 \\
250 & $1.1 \pm 0.1$ & 7.0 & & $1.8 \pm 0.0$ & 2.6 \\
500 & $0.7 \pm 0.1$ & 17.4 & & $1.3 \pm 0.1$ & 9.7 \\
750 & $0.8 \pm 0.1$ & 13.7 & & $1.4 \pm 0.1$ & 5.2 \\
1000 & $0.7 \pm 0.1$ & 8.1 & & $1.3 \pm 0.0$ & 3.3 \\
mean & & 9.5 & & 4.5
\end{tabular}

${ }^{a}$ Glucose was quantified relative to standard curves using HPAE-PAD or by hexokinase-linked assay for samples that underwent SPE. Results are presented as mean $\pm \mathrm{SD}(n=3)$. $\mathrm{SD}=$ standard deviation, \%CV = coefficient of variation.

concentrations of glucose determined enzymatically were 43.0 $\pm 4.3 \%$ lower, but the loss was consistent and readily corrected for using standard curves. Importantly, the $\mathrm{IC}_{50}$ values were not different when determined enzymatically and chromatographically $(677 \pm 241$ and $633 \pm 35 \mu \mathrm{M}$, respectively; 3 independent determinations, $p=0.77$ ) (Figure 7).

3.7. Inhibition of Polyphenols and Extracts on Sucrase and Maltase Activity Using Enzyme from Human and Rat Sources. On the basis of the results from above, the assay conditions for maltase and sucrase were selected and are shown in a flowchart (Figure 8). Using these conditions, the $\mathrm{IC}_{50}$ values for acarbose, green tea, and EGCG for both sucrase and maltase inhibition using the rat and human enzyme sources were determined (Figure 9). The greatest inhibition of human maltase activity was by green tea, with $\mathrm{IC}_{50}$ of $0.5 \mathrm{mg} / \mathrm{mL}$, which contains the equivalent of $\sim 200 \mu \mathrm{M}$ EGCG (most abundant polyphenol). Alone, pure EGCG at $677 \mu \mathrm{M}$ was 


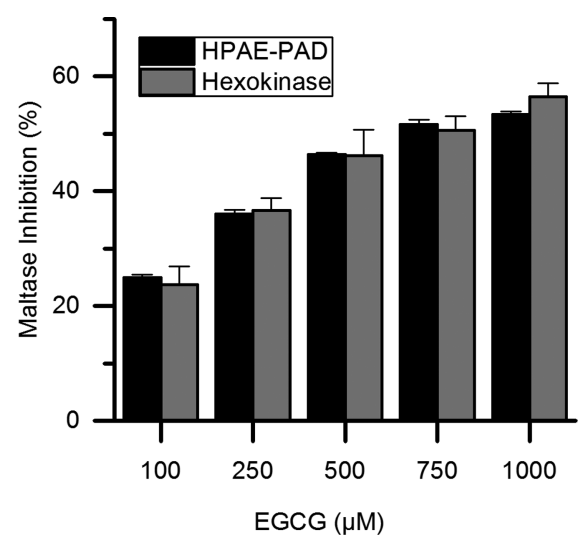

Figure 7. Comparison of glucose detection methods for the inhibition of maltase by EGCG. The amount of glucose produced was determined using HPAE-PAD, or samples were passed through SPE and then glucose determined using the hexokinase assay. The percent inhibition was determined and presented as mean \pm SEM $(n=3)$. There was no significant difference between the two detection methods at any concentration.

required to achieve $50 \%$ inhibition. The $\mathrm{IC}_{50}$ values determined from human and rat enzyme sources for green tea, EGCG, and acarbose are summarized in Table 2. No inhibition was observed for 5-caffeoylquinic acid at $200 \mu \mathrm{M}$ on rat or human maltase and sucrase activities. At a higher concentration of 500 $\mu \mathrm{M}$, human sucrase activity was inhibited by $24 \pm 6.1 \%$ but with no significant inhibition of human maltase.

\section{DISCUSSION}

In recent years, polyphenols have been investigated as potential $\alpha$-glucosidase inhibitors for the management and risk reduction of type 2 diabetes, as an alternative to pharmaceutical treatments such as acarbose. The methods used to date have predominantly used enzyme preparations from rat intestine rather than a human source. ${ }^{30-32}$ The homology between human and rat sucrase-isomaltase is only $74 \%,{ }^{33}$ and so it
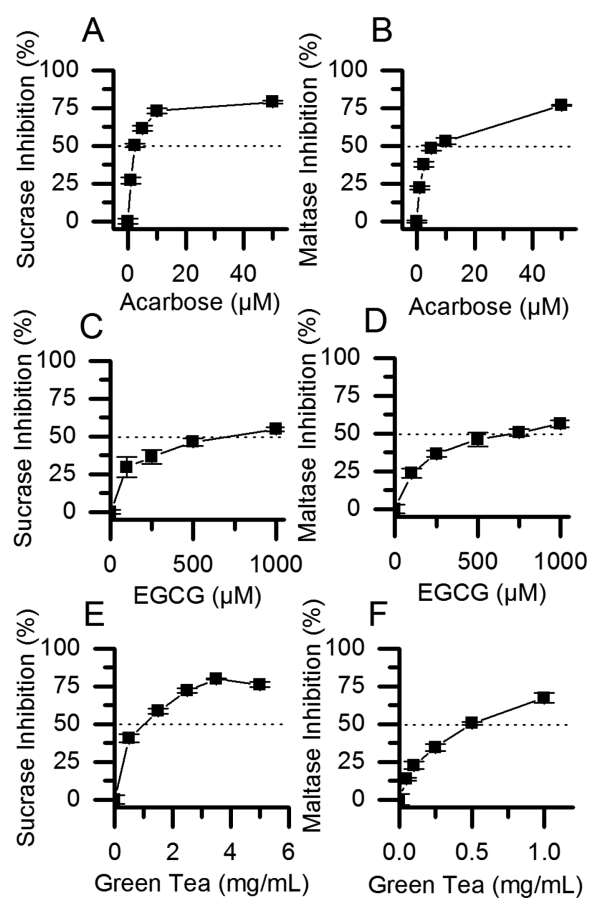

Figure 9. Determination of inhibition of human sucrase and maltase. Determination of $\mathrm{IC}_{50}$ values for sucrase and maltase inhibition by acarbose (A and B), EGCG (C and D), and green tea (E and F). Results are presented as mean $\pm \operatorname{SEM}(n=3)$.

cannot be assumed that inhibition of rat and human enzymes will be equivalent. The active site sequence is conserved, but there are differences in $N$-glycosylation, which can affect inhibition due to steric hindrance. The human sequence has 18 predicted $N$-glycosylation sites, while the rat has 16 , only 9 of which are in equivalent positions. ${ }^{33}$ Furthermore, some reports even use a yeast $\alpha$-glucosidase, which provides much less relevant inhibition information. In congenital sucraseisomaltase deficiency (CSID) disorder, which occurs in $0.2 \%$

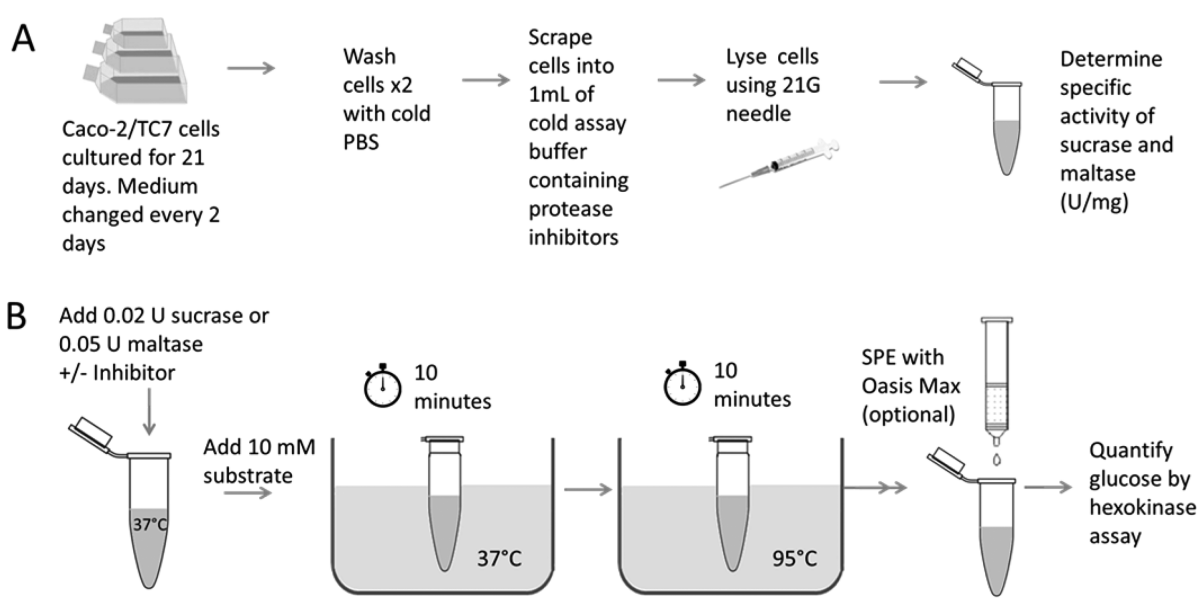

Figure 8. Flowchart showing optimized enzyme assay conditions for determining sucrase and maltase inhibition using human Caco-2/TC7 cells as the enzyme source. (A) Fully differentiated cells are lysed into assay buffer, and the specific activity of sucrase and maltase was determined in the lysate using enzyme assays with a range of enzyme concentrations (40-320 $\mu \mathrm{g}$ total protein). The specific activity is then used to calculate the amount of lysate to give 0.05 units of maltase activity or 0.02 units of sucrase activity. (B) Prewarmed cell lysate and the inhibitor are added to the assay tube, and the reaction is started by the addition of $10 \mathrm{mM}$ substrate (maltose or sucrose). Samples are incubated for $10 \mathrm{~min}$ at $37{ }^{\circ} \mathrm{C}$, and reaction terminated by denaturation at $95{ }^{\circ} \mathrm{C}$ for $10 \mathrm{~min}$. Solid phase extraction is used to remove interfering inhibitors (indicated as optional because it must be determined if the inhibitor interferes with the glucose product determination), and glucose is quantified using the hexokinase assay. 
Table 2. Inhibition of Human and Rat Sucrase and Maltase Activities ${ }^{a}$

\begin{tabular}{|c|c|c|c|c|}
\hline \multirow[b]{2}{*}{ inhibitor } & \multicolumn{2}{|c|}{ human } & \multicolumn{2}{|c|}{ rat } \\
\hline & sucrase $\mathrm{IC}_{50}$ & maltase $\mathrm{IC}_{50}$ & sucrase $\mathrm{IC}_{50}$ & maltase $\mathrm{IC}_{50}$ \\
\hline acarbose $(\mu \mathrm{M})$ & $2.5 \pm 0.5$ & $5.7 \pm 1.4$ & $12.3 \pm 0.6^{b}$ & $0.42 \pm 0.02^{c}$ \\
\hline green tea $(\mathrm{mg} / \mathrm{mL})$ & $1.0 \pm 0.3$ & $0.5 \pm 0.003$ & $1.8 \pm 0.3^{d}$ & $0.035 \pm 0.005^{b}$ \\
\hline EGCG $(\mu \mathrm{M})$ & $657 \pm 150$ & $677 \pm 241$ & $950 \pm 86^{d}$ & $14 \pm 2.0^{b}$ \\
\hline
\end{tabular}

${ }^{a}$ Results are mean $\pm \mathrm{SD}(n=3)$. Acarbose was tested from 1 to $50 \mu \mathrm{M}$; green tea was tested from 0.5 to $5 \mathrm{mg} / \mathrm{mL}$ for sucrase and 0.05 to $1 \mathrm{mg} / \mathrm{mL}$ for maltase, and EGCG was tested from 100 to $1500 \mu \mathrm{M}$ for sucrase and 100 to $1000 \mu \mathrm{M}$ for maltase. Independent sample $t$ test was performed to compare results between rat and human enzymes. ${ }^{b} p<0.001 .{ }^{c} p<0.01 .{ }^{d} p<0.05$.

of people of European descent, genetic differences as small as a point mutation can lead to lack of function. ${ }^{14}$ We therefore confirmed here that the sequence of sucrase-isomaltase in the Caco-2/TC7 cell line is identical to human tissue sucraseisomaltase.

Another limitation of reports currently found in the literature is that the assay parameters and details are not always presented in full, which makes comparison of inhibition values among different reports impossible. Here, an inhibition assay was optimized for sucrase and maltase using human Caco2/TC7 cell-free extracts as an enzyme source (Figure 8). The assay was used to evaluate inhibition by some selected polyphenols and polyphenol-rich extracts and data from the human enzyme source were compared to those determined using a source of rat intestinal enzyme.

The importance of optimizing the assay was demonstrated because working kinetically outside of initial rates ${ }^{34}$ changed the measured inhibition by acarbose. Substrate concentration, although reported to be important when measuring inhibition, ${ }^{35}$ was less critical. Papain proteolytically cleaves the isomaltase stalk from the membrane, ${ }^{36}$ resulting in higher specific activity for both sucrase and maltase. Because inhibition of maltase by acarbose was the same whether the enzyme was free or membrane-bound, this was not considered to be a critical step to carry out for an optimized assay. When considering methods for detecting glucose as the product, both enzymatic (hexokinase) and chromatographic detection gave equivalent $\mathrm{IC}_{50}$ values, but the latter gave a lower coefficient of variation. Critically, if the putative inhibitor interferes with the glucose detection method, then solid phase extraction was absolutely necessary before the step to determine glucose.

EGCG, green tea, and acarbose exhibited 1.4 to 4.8 -fold stronger inhibition of human sucrase compared to rat; for maltase, the reverse was true ( 13.5 to 48 -fold weaker). Sucrase activity arises solely from the sucrase subunit of sucraseisomaltase, whereas maltase is derived from both the isomaltase and sucrase subunits ${ }^{16}$ as well as other $\alpha$-glucosidases such as maltase glucoamylase (MGAM) ${ }^{16}$ In humans, SI provides the majority of the maltase and of the isomaltase activities in the intestinal brush border. ${ }^{33}$ MGAM is absent from Caco- 2 cells, ${ }^{37}$ and it is a less-important enzyme for hydrolysis of sucrose and maltase. Therefore, our method is specific for analyzing inhibition of the brush border sucrase-isomaltase enzyme, which also hydrolyses the majority of maltose in the intestine. Our data suggest that the tested inhibitors are more effective on human compared to rat sucrase, and therefore, more substantial effects might be expected in humans compared to rats in vivo, but there is not enough data in the literature to make this direct in vivo comparison. This situation also applies in reverse for maltase inhibition.

The $\mathrm{IC}_{50}$ of EGCG for rat sucrase has been reported to be $218^{32}$ and $169 \mu \mathrm{M},{ }^{30}$ both stronger than we observed here using rat enzyme; however, both used detection methods in which EGCG interferes. ${ }^{38}$ The IC $_{50}$ of EGCG for rat maltase has been reported as $40 \mu \mathrm{M}$, somewhat weaker than that observed here $(14 \mu \mathrm{M})$. Reported results using the enzyme from rat sources for acarbose, which does not interfere with detection methods, were more comparable to ours $\left(\mathrm{IC}_{50}\right.$ of 0.43 $\mu \mathrm{M}$ for maltase and $1.2 \mu \mathrm{M}$ for sucrase). ${ }^{30}$ 5-Caffeoylquinic acid was reported to strongly inhibit maltase activity with $K_{\mathrm{i}}=$ $1.8 \mu \mathrm{M}$ using a Drosophila expression system as the source of mouse sucrase, ${ }^{39}$ but we did not observe inhibition of human maltase even at $500 \mu \mathrm{M}$, and only weak inhibition of human sucrase. Hence, 5-caffeoylquinic acid is not expected to have any physiologically-relevant inhibiting effects in humans, even though it was previously reported to be a strong inhibitor. Interference in the detection method, or the use of the mouse sequence for the expression, could partially explain the dramatic difference. Furthermore, glycosylation in the Drosophila expression system differs from mammalian: it lacks the ability to produce complex $N$-glycans due to the absence of $\beta$-Nacetylglucosaminidase. ${ }^{40}$

Use of the pharmacological strong inhibitor acarbose often leads to gastrointestinal side effects ${ }^{41}$ due to substantial amounts of undigested starch and sugar reaching the colon. Dietary compounds such as polyphenols exhibit weaker but significant inhibition when tested in volunteers in vivo, ${ }^{21}$ are consumed every day, and show fewer side effects. Other classes of compounds may also demonstrate activity. For example, the naturally occurring pentose sugar L-arabinose, which is a specific sucrase inhibitor, did not cause gastrointestinal side effects in humans. ${ }^{19}$ Digestion of sucrose by sucrase can be ratelimiting in the glycemic response in rats; in an oral sucrose tolerance test with a formulation containing L-arabinose, the incremental area under the curve for blood glucose was significantly reduced, while no change was observed in comparable glucose or starch tests. ${ }^{42,43}$ In humans, pure Larabinose led to a delay in glucose absorption in response to sucrose intake, and although there was no change in iAUC, there were significant positive changes in the hormones GLP-1, GIP, and insulin. ${ }^{19}$

In summary, we report an optimized assay for estimating inhibition of human sucrase and maltase activities derived from the sucrase-isomaltase enzyme. When performing assays or considering published inhibition data, any interference with the glucose detection methodology must be considered, and interfering compounds removed through SPE. Because this introduces some variation, HPAE-PAD offers an alternative detection method which can improve accuracy because SPE is not required. The current work highlights that the use of human cells or rat tissues as the source of $\alpha$-glucosidase activities impacts the resulting inhibition and should be carefully considered and reported to avoid reporting false negatives or positives. 


\section{ASSOCIATED CONTENT}

\section{S Supporting Information}

The Supporting Information is available free of charge on the ACS Publications website at DOI: 10.1021/acs.jafc.7b03678.

Primer lists and results from cDNA sequencing (PDF)

\section{AUTHOR INFORMATION}

\section{Corresponding Author}

*E-mail g.williamson@leeds.ac.uk; Telephone: +44 (0)113 3438380; Fax: +44(0)113 3432982.

ORCID

Gary Williamson: 0000-0002-5624-6267

\section{Funding}

The research leading to these results received funding from the European Research Council Advanced Grant 322467 ("POLYTRUE?”) and from the Biotechnology and Biological Sciences Research Council, UK (BBSRC DRINC BB/M027406/1). H.N.-S. is grateful to the Commonwealth Scholarship Commission, U.K. (Grant ZMCS-2012-593) and the National Institute for Scientific and Industrial Research (NISIR), Zambia for Ph.D funding.

\section{Notes}

The authors declare no competing financial interest.

\section{ACKNOWLEDGMENTS}

Kind regards to Lynn McKeown, University of Leeds, for her support and training for the gene sequencing.

\section{ABBREVIATIONS USED}

App, apparent; CSID, congenital sucrase-isomaltase deficiency; DMSO, dimethyl sulfoxide; EGCG, (-)-epigallocatechin gallate; GIP, gastric inhibitory polypeptide; GLP-1, glucagon-like peptide 1 ; HPAE-PAD, high performance anion exchange chromatography with pulsed amperometric detection; iAUC, incremental area under the curve; $\mathrm{IC}_{50}$, half maximal inhibitory concentration; MGAM, maltase glucoamylase; PBS, phosphate-buffered saline; SI, sucrase-isomaltase; SPE, solid phase extraction

\section{REFERENCES}

(1) WHO. World Health Organisation: World Health Statistics 2012. http://www.who.int/gho/publications/world_health_statistics/2012/ en/ (accessed February 2, 2017).

(2) Livesey, G.; Taylor, R.; Hulshof, T.; Howlett, J. Glycemic response and health-a systematic review and meta-analysis: relations between dietary glycemic properties and health outcomes. Am. J. Clin. Nutr. 2008, 87, 258S-268S.

(3) Breuer, H. W. Review of acarbose therapeutic strategies in the long-term treatment and in the prevention of type 2 diabetes. Int. J. Clin. Pharmacol. Ther. 2003, 41, 421-40.

(4) Nijpels, G.; Boorsma, W.; Dekker, J.; Kostense, P.; Bouter, L.; Heine, R. A study of the effects of acarbose on glucose metabolism in patients predisposed to developing diabetes: the Dutch acarbose intervention study in persons with impaired glucose tolerance (DAISI). Diabetes/Metab. Res. Rev. 2008, 24, 611-616.

(5) Laville, M.; Nazare, J. A. Diabetes, insulin resistance and sugars. Obes. Rev. 2009, 10, 24-33.

(6) Hanhineva, K.; Torronen, R.; Bondia-Pons, I.; Pekkinen, J.; Kolehmainen, M.; Mykkanen, H.; Poutanen, K. Impact of dietary polyphenols on carbohydrate metabolism. Int. J. Mol. Sci. 2010, 11, 1365-402.
(7) Scalbert, A.; Manach, C.; Morand, C.; Rémésy, C.; Jiménez, L. Dietary Polyphenols and the Prevention of Diseases. Crit. Rev. Food Sci. Nutr. 2005, 45, 287-306.

(8) Williamson, G. Possible effects of dietary polyphenols on sugar absorption and digestion. Mol. Nutr. Food Res. 2013, 57, 48-57.

(9) Jo, S.; Ka, E.; Lee, H.; Apostolidis, E.; Jang, H.; Kwon, Y. Comparison of antioxidant potential and rat intestinal a-glucosidases inhibitory activities of quercetin, rutin, and isoquercetin. Int. J. Appl. Res. Nat. Prod. 2009, 2, 52-60.

(10) Gupta, S.; Mahmood, S.; Khan, R. H.; Mahmood, A. Inhibition of brush border sucrase by polyphenols in mouse intestine. Biosci. Rep. 2009, 30, 111-117.

(11) Kim, S.-H.; Jo, S.-H.; Kwon, Y.-I.; Hwang, J.-K. Effects of onion (Allium cepa L.) extract administration on intestinal $\alpha$-glucosidases activities and spikes in postprandial blood glucose levels in SD rats model. Int. J. Mol. Sci. 2011, 12, 3757-3769.

(12) Priscilla, D. H.; Roy, D.; Suresh, A.; Kumar, V.; Thirumurugan, K. Naringenin inhibits $\alpha$-glucosidase activity: A promising strategy for the regulation of postprandial hyperglycemia in high fat diet fed streptozotocin induced diabetic rats. Chem.-Biol. Interact. 2014, 210, $77-85$.

(13) Xu, H.; Leng, X.; Wang, M. Z.; Zhang, G. Y. Glucose Measurement in the Presence of Tea Polyphenols. Food Anal Method 2012, 5, 1027-1032.

(14) Naim, H. Y.; Heine, M.; Zimmer, K.-P. Congenital sucraseisomaltase deficiency: heterogeneity of inheritance, trafficking, and function of an intestinal enzyme complex. J. Pediatr. Gastroenterol. Nutr. 2012, 55, S13-S20.

(15) Quan, R.; Gray, G. M. Sucrase-alpha-dextrinase in the rat. Postinsertional conversion to inactive molecular species by a carbohydrate-free diet. J. Clin. Invest. 1993, 91, 2785-2790.

(16) Jones, K.; Sim, L.; Mohan, S.; Kumarasamy, J.; Liu, H.; Avery, S.; Naim, H. Y.; Quezada-Calvillo, R.; Nichols, B. L.; Mario Pinto, B.; Rose, D. R. Mapping the intestinal alpha-glucogenic enzyme specificities of starch digesting maltase-glucoamylase and sucraseisomaltase. Bioorg. Med. Chem. 2011, 19, 3929-3934.

(17) Dyer, J.; Wood, I. S.; Palejwala, A.; Ellis, A.; Shirazi-Beechey, S. P. Expression of monosaccharide transporters in intestine of diabetic humans. Am. J. Physiol. Gastrointest. Liver Physiol. 2002, 282, G241G248.

(18) Hansawasdi, C.; Kawabata, J. $\alpha$-Glucosidase inhibitory effect of mulberry (Morus alba) leaves on Caco-2. Fitoterapia 2006, 77, 568573.

(19) Krog-Mikkelsen, I.; Hels, O.; Tetens, I.; Holst, J. J.; Andersen, J. $\mathrm{R}$; Bukhave, K. The effects of L-arabinose on intestinal sucrase activity: dose-response studies in vitro and in humans. Am. J. Clin. Nutr. 2011, 94, 472-478.

(20) Jockovic, N.; Fischer, W.; Brandsch, M.; Brandt, W.; Drager, B. Inhibition of human intestinal alpha-glucosidases by calystegines. J. Agric. Food Chem. 2013, 61, 5550-7.

(21) Nyambe-Silavwe, H.; Williamson, G. Polyphenol-and fibre-rich dried fruits with green tea attenuate starch-derived postprandial blood glucose and insulin: a randomised, controlled, single-blind, cross-over intervention. Br. J. Nutr. 2016, 116, 443-450.

(22) Auricchio, S.; Dahlqvist, A.; Semenza, G. Solubilization of the human intestinal disaccharidases. Biochim. Biophys. Acta, Spec. Sect. Enzymol. Subj. 1963, 73, 582-587.

(23) Bradford, M. M. A rapid and sensitive method for the quantitation of microgram quantities of protein utilizing the principle of protein-dye binding. Anal. Biochem. 1976, 72, 248-254.

(24) Weitzhandler, M.; Barreto, V.; Pohl, C.; Jandik, P.; Cheng, J.; Avdalovic, N. CarboPac PA20: a new monosaccharide separator column with electrochemical detection with disposable gold electrodes. J. Biochem. Biophys. Methods 2004, 60, 309-317.

(25) Rohrer, J., Analysis of Carbohydrates by High-Performance Anion-Exchange Chromatography with Pulsed Amperometric Detection (HPAE-PAD). Thermo Fisher Scientific, Technical Note 2012, 20.1

(26) Chantret, I.; Lacasa, M.; Chevalier, G.; Ruf, J.; Islam, I.; Mantei, N.; Edwards, Y.; Swallow, D.; Rousset, M. Sequence of the complete 
cDNA and the $5^{\prime}$ structure of the human sucrase-isomaltase gene. Possible homology with a yeast glucoamylase. Biochem. J. 1992, 285, 915-923.

(27) Strausberg, R. L. Generation and initial analysis of more than 15,000 full-length human and mouse cDNA sequences. Proc. Natl. Acad. Sci. U. S. A. 2002, 99, 16899-16903.

(28) Trugnan, G.; Rousset, M.; Zweibaum, A. Castanospermine: a potent inhibitor of sucrase from the human enterocyte-like cell line Caco-2. FEBS Lett. 1986, 195, 28-32.

(29) Wong, A. I. C.; Huang, D. J. Assessment of the Degree of Interference of Polyphenolic Compounds on Glucose Oxidation/ Peroxidase Assay. J. Agric. Food Chem. 2014, 62, 4571-4576.

(30) Matsui, T.; Tanaka, T.; Tamura, S.; Toshima, A.; Tamaya, K.; Miyata, Y.; Tanaka, K.; Matsumoto, K. $\alpha$-Glucosidase inhibitory profile of catechins and theaflavins. J. Agric. Food Chem. 2007, 55, 99-105.

(31) Kamiyama, O.; Sanae, F.; Ikeda, K.; Higashi, Y.; Minami, Y.; Asano, N.; Adachi, I.; Kato, A. In vitro inhibition of $\alpha$-glucosidases and glycogen phosphorylase by catechin gallates in green tea. Food Chem. 2010, 122, 1061-1066.

(32) Honda, M.; Hara, Y. Inhibition of rat small intestinal sucrase and $\alpha$-glucosidase activities by tea polyphenols. Biosci., Biotechnol., Biochem. 1993, 57, 123-124.

(33) Van Beers, E. H.; Büller, H. A.; Grand, R. J.; Einerhand, A. W. C.; Dekker, J. Intestinal brush border glycohydrolases: structure, function, and development. Crit. Rev. Biochem. Mol. Biol. 1995, 30, $197-262$.

(34) Bisswanger, H. Enzyme assays. Perspect. Sci. 2014, 1, 41-55.

(35) Acker, M. G.; Auld, D. S. Considerations for the design and reporting of enzyme assays in high-throughput screening applications. Perspect. Sci. 2014, 1, 56-73.

(36) Brunner, J.; Hauser, H.; Braun, H.; Wilson, K. J.; Wacker, H.; O'Neill, B.; Semenza, G. The mode of association of the enzyme complex sucrase. isomaltase with the intestinal brush border membrane. J. Biol. Chem. 1979, 254, 1821-1828.

(37) Hauri, H. P.; Sterchi, E. E.; Bienz, D.; Fransen, J. A.; Marxer, A. Expression and intracellular transport of microvillus membrane hydrolases in human intestinal epithelial cells. J. Cell Biol. 1985, 101, $838-851$.

(38) Nyambe-Silavwe, H.; Villa-Rodriguez, J. A.; Ifie, I.; Holmes, M.; Aydin, E.; Jensen, J. M.; Williamson, G. Inhibition of human $\alpha$-amylase by dietary polyphenols. J. Funct. Foods 2015, 19, 723-732.

(39) Simsek, M.; Quezada-Calvillo, R.; Ferruzzi, M. G.; Nichols, B. L.; Hamaker, B. R. Dietary Phenolic Compounds Selectively Inhibit the Individual Subunits of Maltase-Glucoamylase and SucraseIsomaltase with the Potential of Modulating Glucose Release. J. Agric. Food Chem. 2015, 63, 3873-3879.

(40) Léonard, R.; Rendić, D.; Rabouille, C.; Wilson, I. B.; Préat, T.; Altmann, F. The Drosophila fused lobes gene encodes an $\mathrm{N}$ acetylglucosaminidase involved in N-glycan processing. J. Biol. Chem. 2006, 281, 4867-4875.

(41) Balfour, J. A.; McTavish, D. Acarbose. Drugs 1993, 46, 10251054.

(42) Preuss, H. G.; Echard, B.; Bagchi, D.; Stohs, S. Inhibition by natural dietary substances of gastrointestinal absorption of starch and sucrose in rats and pigs: 1 . Acute studies. Int. J. Med. Sci. 2007, 4, 196202.

(43) Preuss, H. G.; Echard, B.; Bagchi, D.; Stohs, S. Inhibition by natural dietary substances of gastrointestinal absorption of starch and sucrose in rats 2. Subchronic studies. Int. J. Med. Sci. 2007, 4, 209-15. 